Balbinder, E. \& Preer, Jun., J. R. (1959). J. gen. Microbiol. 21, 156-167

\title{
Gel Diffusion Studies on Serotype and Serotype Transformation in Paramecium
}

\author{
By E. BALBINDER* and J. R. PREER, Jun. \\ Zoological Laboratory, University of Pennsylvania, Philadelphia, \\ Pennsylvania, U.S.A.
}

\begin{abstract}
SUMMARY: Antigens G and E of stock 28 variety 2 of Paramecium aurelia show cross-reactions with their respective antisera in immobilization and gel diffusion tests. In immobilization tests the anti-E serum $P$, no. 132, shows the strongest cross-reaction; in gel diffusion tests the anti-G serum $P$, no. 130, cross reacts more strongly. During serotype transformation of type $G$ protozoa to type $E$, the increase of the $\mathbf{E}$ antigen and the disappearance of the $\mathrm{G}$ antigen were followed by the gel diffusion technique. However, because of the peculiar cross-reactions of these two antigens, only the increase of the new (E) antigen was studied quantitatively by this technique. No reliable measurements of the loss of the old (G) antigen were obtained. The results indicate that during transformation the amount of the new antigen increased exponentially.
\end{abstract}

Within a given stock of Paramecium aurelia a number of clones representing different antigenic types or serotypes may be obtained. Each clone is immobilized by an appropriate dilution of homologous antiserum made against protozoa of its own serotype and unaffected by similar dilutions of sera made against other serotypes. Studies of the immobilization antigens of Paramecium by Sonneborn and others have revealed that they are determined by a complex interaction of three factors: the environment, a system of cytoplasmic inheritance, and nuclear genes (review; see Beale, 1957). Changes in the environment often induce a transformation from one serotype to another. Often the different serotypes of a stock are stable under the same environmental conditions. Under such circumstances crosses between the different serotypes reveal that the differences are maintained by a system of cytoplasmic inheritance. The serotypes which can be manifested, their specific properties and also their stability have been shown to vary from stock to stock, and to be under the control of nuclear genes.

The data are consistent with the idea that there is a separate primary genic locus for each serotype, a locus which influences whether the serotype in Paramecium aurelia can be expressed, its stability, and its immunological specificity. More than one locus, however, may be involved in stability. Normally, the effect of only one primary locus is evidenced at any one time, i.e. only one antigen is detectable. In most of the cases studied any one of a number of equally competent loci may come to expression under a particular set of conditions. Once a type is expressed, however, the continued expression of that locus rather than the others is transmitted hereditarily through the

\footnotetext{
* Present address: Carnegie Institution of Washington, Department of Genetics, Cold Spring Harbor, Long Island, New York, U.S.A.
} 
cytoplasm. The expression of one locus may be suppressed and another allowed to be manifested by changing the conditions of culture.

The phenomenon of transformation of protozoa of one serotype into another is of particular interest from the point of view of gene action during development and differentiation. Upon transformation the action of a given locus ceases to be manifested and the effect of another appears. During the period of transition (about two fissions) both the disappearing serotype and the new one coming to expression may be detected at the same time (Beale, 1948, 1954; Margolin, 1956).

Studies of the transformation process have been hampered until recently by the lack of a quantitative method for assay of the antigen. This difficulty was overcome by Finger (1956) who used a technique of precipitation in a gel. Gel-diffusion techniques provide a qualitative and quantitative method of measuring antigens in complex mixtures (Oudin, 1952; Oakley \& Fulthorpe, 1953; Preer, 1956; Preer \& Telfer, 1957). Finger found that while protozoa of different serotype contained many common antigens, each immobilization serotype had a unique antigen not found in any of the others. Preer \& Preer (1959) studied a series of antigens obtained from protozoa of one serotype, designating them antigens 1, 2, 3 and 4. Antigen 4 was the serotype correlated antigen described by Finger. As shown by Finger, there are a number of serologically different antigens 4, each corresponding to a specific immobilization serotype. It is assumed that these antigens are the immobilization antigens, and they will be referred to as antigens A, B, C, etc., corresponding to the serotypes from which they are obtained. Preer \& Preer (1959) reported that antigen G of variety 2 of Paramecium aurelia has the properties of a protein and is localized in the cilia and pellicle. Beale \& Kacser (1957), using fluorescent antibody, reached similar conclusions about the site of the immobilization antigens in variety 1.

The present paper reports the results of a preliminary study of the kinetics of serotype transformation in Paramecium aurelia by using gel diffusion quantitatively to assay antigen. The transformation studied was from serotype G to serotype $\mathrm{E}$ in stock 28 of variety 2 of $P$. aurelia (Finger, 1957 a). The two serotypes proved to cross-react rather strongly in gel diffusion and it was necessary to devote special attention to the immunological relations between the two antigens and their antibodies. Serotype $G$ is stable at $12^{\circ}$ and transforms to $\mathrm{E}$ when the protozoa are transferred to $31^{\circ}$ and cultivated at one fission/day, transformation being completed in 2-3 days.

\section{METHODS}

Organisms. Transformation was followed in Paramecium aurelia, variety 2, stock 28, originally isolated at Woods Hole, Massachusetts, U.S.A. Sera prepared against stock 3, isolated at Baltimore, Maryland, U.S.A., were also used. It should be noted that the variety 2 serotype $G$, considered here appears to be related to the serotype $\mathbf{G}$ of other varieties of $\boldsymbol{P}$. aurelia (cf. Sonneborn, 1948; Beale, 1952). The variety 2 serotype $E$, however, is not related to the serotype $\mathrm{E}$ of variety 4 described by Sonneborn (1948). 
Culture medium. The culture medium was: $0 \cdot 15 \%(\mathrm{w} / \mathrm{v})$ Cerophyl infusion (Cerophyl Laboratories, Kansas City, Kansas, U.S.A.) with 1 g. $\mathrm{Na}_{2} \mathrm{HPO}_{4} \cdot 12 \mathrm{H}_{2} \mathrm{O} / 1$. The medium was inoculated with Aerobacter cloacae 1 or 2 days before use.

Antisera. Three antisera were used. Antigen was given intravenously to rabbits over a period of 3 weeks at two injections/week. Bleedings were made 1 week after the last injection. Serum $P$, no. 113, was made by injecting $5 \times 10^{6}$ homogenized protozoa of stock 3 , serotype $G$, according to the method of Sonneborn (1950). This was used for immobilization tests. Serum P, no. 130, was made by injecting the cilia (see Preer \& Preer, 1959) from $5 \times 10^{6}$ organisms of stock 3, serotype G. It was used for immobilization and precipitation tests, and gave only one zone of precipitation in gel diffusion tests against whole homogenates: that due to the serotype correlated antigen $\mathbf{G}$. Serum $\mathbf{P}$, no. 132, was obtained by injecting the cilia and trichocysts from $5 \times 10^{6}$ organisms of stock 28 , serotype $\mathrm{E}$. It was useful in both immobilization and gel diffusion tests. In gel diffusion tests, however, it was found to have a titre against certain heat stable non-immobilization antigens, as well as the heat-labile serotype correlated antigen. These heat stable antigens included the trichocyst antigen 1 (Preer \& Preer, 1959). Bands due to these antigens were removed by absorbing the serum with an extract of boiled paramecia: $4 \times 10^{6}$ organisms of stock 3 , serotype $\mathrm{G}$, were suspended in $1 \mathrm{ml}$. saline and boiled for $10 \mathrm{~min}$. Of the supernatant fluid, $0.143 \mathrm{ml}$. was added to $1 \mathrm{ml}$. of serum $\mathbf{P}$, no. 132, to prepare the absorbed serum. It was then specific for immobilization antigen.

Antigens. Paramecia were filtered through sixteen layers of cheesecloth and concentrated by passing through a Massey-Harris automatic cream separator, modified as described by Preer \& Preer (1959). A population count was carried out according to the method described by Sonneborn (1950). Further concentration was achieved by centrifuging for $2 \mathrm{~min}$. in an International electric oil-testing centrifuge at $700 \mathrm{~g}$. The supernatant fluid was discarded and the paramecia were resuspended in $0.45 \mathrm{M}-\mathrm{KCl}$ solution to a concentration of $1.5 \times 10^{6}$ organisms $/ \mathrm{ml}$. and were then homogenized at $0^{\circ}$ by using a special homogenizer with a tight-fitting Teflon tissue plunger. The homogenate was allowed to extract in a refrigerator for $24 \mathrm{hr}$. and was then centrifuged for $2 \mathrm{~min}$. at $0^{\circ}$ at $25,000 \mathrm{~g}$ in the high-speed head of an International refrigerated centrifuge. The supernatant fluid containing the soluble antigen was then stored in a deep-freeze until needed.

Gel diffusion tests. Assays were conducted by a technique of double diffusion in agar (Preer, 1956). About 0.01 ml. of serum was placed in the bottom of an agar-coated Pyrex tube of $3 \mathrm{~mm}$. outside diameter; $0.6 \%(\mathrm{w} / \mathrm{v})$ agar in $0.9 \%(\mathrm{w} / \mathrm{v})$ saline with $0.01 \%(\mathrm{w} / \mathrm{v})$ thiomersalate at $60^{\circ}$ was layered on to the serum to a depth of about $5 \mathrm{~mm}$. and allowed to solidify. About $0.01 \mathrm{ml}$. of antigen was then layered on to the agar, and the tube capped with Picene cement. Tubes were placed at $\mathbf{2 5}^{\circ}$, oriented horizontally, in order to minimize convection currents in the liquid layer (Preer \& Telfer, 1957; Preer \& Preer, 1959). At the region in the agar column where antigen diffusing from 
above met with specific antibodies diffusing from the serum layer below the agar, a band of precipitation was formed. Band positions were determined after one day with the aid of a low-power binocular microscope with a scale in one of the eyepieces. Positions were expressed as $p$, the distance from the antigen-agar interface to the centre of the 'band' (zone of precipitation) divided by the total agar length. Band position, $p$, is linearly related to the ratio of the concentration of the antigen to the concentration of the antibody (Preer, 1956). Thus, when antibody concentration is held constant, increases in the concentration of antigen result in displacement of the bands away from the antigen-agar interface. Hence a series of standard dilutions of the required antigen set against samples of a standard serum provided a reference curve for determining relative antigen concentrations. Absorption, or blocking tests, were performed by adding antigen to antiserum and then setting diffusion tubes with the mixture.

Experimental procedure. Cultures of stock 28, serotype G, were grown at $12^{\circ}$ in 21 . Erlenmeyer flasks and fed enough to allow no more than one fission every 10 days (Sonneborn, 1950), on the average. When a population of suitable size had been reached, the organisms were supplied with enough food to undergo one fission/day and transferred to $31^{\circ}$ for transformation to proceed. At zero time (before transfer to $31^{\circ}$ ) and at frequent intervals during the transformation process, samples of the culture were removed and the immobilization titres for both serotypes $\mathbf{G}$ and $\mathbf{E}$ determined according to the methods described by Sonneborn (1950). Other organisms from the samples were extracted as described above in order to obtain antigens for gel diffusion tests. Every $24 \mathrm{hr}$. enough food was added to the cultures to maintain the rate of one fission/day. This process was continued for 4 days, long after transformation had been completed. Soluble antigen was then assayed by setting gel diffusion tests with suitable serum.

\section{RESULTS}

\section{Antigens $\boldsymbol{G}$ and $\boldsymbol{E}$ and their cross-reactions}

The immobilization titres (the greatest serum dilution giving complete and partial immobilization in $2 \mathrm{hr}$. at $27^{\circ}$ ) are given in Table 1 , for the three sera and serotypes $\mathbf{G}$ and $\mathbf{E}$ of stock 28 . It may be noted that, although each serum reacted best with its homologous serotype, cross-reactions were also observed, particularly in the case of the anti-E serum. Such cross-reactions have long been known (Sonneborn, 1947). Nevertheless, the cross-reactions observed here were somewhat greater than usually found between different serotypes of a single stock. It is unlikely in this case that the cross-reactions were due simply to the injection of a few organisms of the cross-reacting type in preparing the antiserum, since tests on samples of the paramecia used for injection contained none of the cross-reacting types. This evidence was especially convincing in the case of the anti-G sera, which were prepared against stock 3. Stock 3 has never been known to manifest serotype $\mathbf{E}$; it probably lacks the gene for this type, just as do similar stocks studied by Finger (1957b). 
In gel diffusion tests cross-reactions were even more marked. The anti-G serum $P$, no. 130, gave a zone of precipitation of almost equal intensity and position with both $\mathbf{G}$ and $\mathbf{E}$ antigens, and mixtures of the two antigens in

Table 1. The effect of several sera on serotypes $\boldsymbol{G}$ and $\boldsymbol{E}$ of stock 28 of Paramecium aurelia

The highest dilution of serum giving complete immobilization and the highest dilution giving a visible effect in 2-hr. tests are given for each serotype and serum.

$\begin{array}{cccccc} & \begin{array}{c}\text { Complete } \\ \text { immobilization }\end{array} & \begin{array}{c}\text { Visible } \\ \text { effect }\end{array} & & \overbrace{\begin{array}{c}\text { Complete } \\ \text { immobilization }\end{array}}^{\text {Serotype E }} & \begin{array}{c}\text { Visible } \\ \text { effect }\end{array} \\ \begin{array}{c}\text { Anti-G serum } \\ \text { P, no. } 113\end{array} & 1 / 25 & 1 / 400 & - & 1 / 50 \\ \begin{array}{c}\text { Anti-G serum } \\ \text { P, no. } 130\end{array} & 1 / 25 & 1 / 800 & - & 1 / 25 \\ \begin{array}{c}\text { Anti-E serum } \\ \text { P, no. } 132\end{array} & 1 / 12.5 & 1 / 100 & 1 / 100 & 1 / 1600\end{array}$

varying ratios still yielded only one band. When the serum was absorbed with large quantities of the heterologous $E$ antigen, no band was obtained with the $\mathbf{E}$ or $\mathbf{G}$ antigens. Absorption with a critical amount of $\mathbf{E}$ (near the equivalence ratio) produced a serum which did not give a band with the $\mathrm{E}$ antigen, but did with the homologous $\mathrm{G}$ antigen. However, such absorbed serum, while producing a zone of precipitation with the $\mathbf{G}$ and not $\mathbf{E}$ antigens and providing a

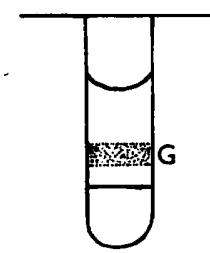

Tube no. 1

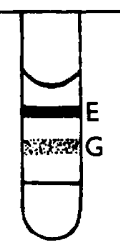

2
Time of transformation 0

(hr.) (pure G)

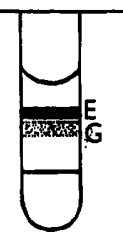

3

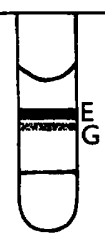

4

42

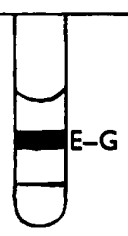

5

54

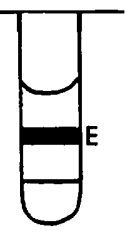

6

92

(pure E)

Fig. 1. Diagram of double diffusion tests on antigen extracts made from stock 28 paramecia at different intervals during transformation from serotype $G$ to serotype $\mathbf{E}$. All antigen extracts were set against anti-E serum $P$, no. 132. The serum, which normally contained antibodies against certain heat stable antigens as well as the heatlabile serotype correlated antigens, was made specific for the latter by absorption with an extract of boiled paramecia. Each tube was set against antigen extracted after the following periods of transformation : tube $1,0 \mathrm{hr}$. (pure G); tube $2,18 \mathrm{hr}$.; tube 3, $30 \mathrm{hr}$.; tube 4, 42 hr.; tube 5, 54 hr.; tube 6, $92 \mathrm{hr}$. (pure E). Serum P, no. 132, cross-reacted with antigen $G$, resulting in a fairly weak band (tube 1 ) which was clearly different from the band obtained with antigen $E$ (tube 6). Two bands were formed while transformation was in progress (tubes 2,3 and 4). The lower and weaker band was the one formed by antigen $G$; the upper and sharper band was formed by antigen $E$. For further details see text.

qualitative test for $\mathrm{G}$, proved useless in estimating the quantity of $\mathrm{G}$ antigen in the presence of $\mathrm{E}$ antigen. 'This was true because the addition of $\mathrm{E}$ antigen to extracts of $\mathrm{G}$ was found to displace the precipitation zone toward the serum- 
agar interface. Furthermore, the degree of displacement depended upon the quantity of $\mathbf{E}$ added. Since band position is the basis for the quantitative gel diffusion test, no means for measuring the quantity of $G$ antigen in the presence of $E$ was available with serum $P$, no. 130, as well as other anti-G sera.

The anti-E serum $\mathbf{P}$, no. 132, also cross-reacted in gel diffusion tests, but less strongly than the $\mathrm{G}$ serum and in a somewhat different way. It gave a sharp band with the homologous $\mathrm{E}$ antigen and a weak band displaced toward the agar-serum interface with $\mathrm{G}$ antigen (see Fig. 1). When small quantities of $G$ antigen were added to $E$ antigen and set against serum $P$, no. 132, a single band was obtained with position and appearance just as if the $\mathrm{E}$ antigen were set unmixed. When larger quantities of $\mathrm{G}$ antigen were added to $\mathbf{E}$, two bands appeared. The upper band toward the antigen-agar interface had the position and appearance of the $\mathbf{E}$ band, just as if no $\mathrm{G}$ antigen had been

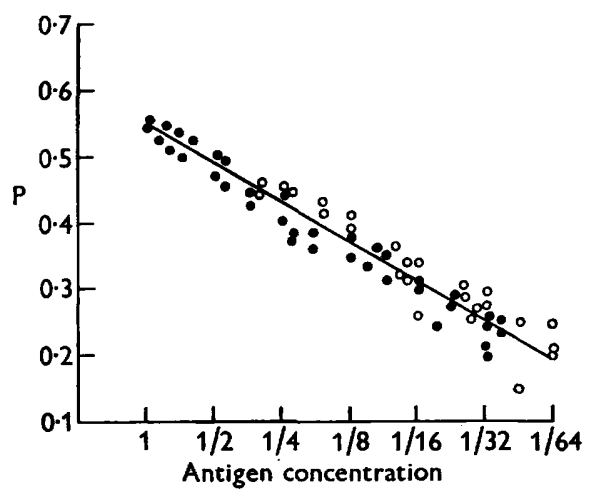

Fig. 2. Relation between band position $p$ and antigen concentration for the $E$ antigen set against anti-E serum $P$, no. 132 . $G$ extract was present in different amounts. For the points indicated with solid circles the $\mathbf{E}$ extract was in excess, the $\mathbf{G}: \mathbf{E}$ ratio ranging from $0: 1$ to $1: 2$. For the points indicated with open circles the $G$ antigen was in excess, the $G: E$ ratio ranging from $2: 1$ to $31: 1$.

added, while the lower band (toward the serum-agar interface) was weak and appeared to be due to the $\mathrm{G}$ antigen. Addition of still larger concentrations of $G$ antigen to the $\mathbf{E}$ gave no change in the upper $\mathbf{E}$ band, but progressively lowered the bottom band, showing clearly that it was due to the $\mathbf{G}$ antigen. It was thus evident that serum $P$, no. 132 , could be used to determine the concentration of the $\mathbf{E}$ antigen, even in the mixtures of $E$ and $G-$ the $E$ precipitation zone being recognized as a single, intense band, or as the upper band when two were formed. Since some of the antibody is precipitated by the $\mathrm{G}$ antigen in mixtures, one might expect an effect on the position of the $\mathrm{E}$ band. However, the proportion of the total antibody precipitated by the $\mathrm{G}$ antigen must be small, for no such displacement was noted. A standard curve relating the position of the $\mathbf{E}$ band to the concentration of the $\mathbf{E}$ antigen appears in Fig. 2. G antigen was present in most of the determinations and the ratio of $\mathbf{G}$ to $\mathbf{E}$ varied from $0: 1$ to $31: 1$. It can be seen that all the points fall on a 
straight line. When the data were classified according to the $\mathbf{G}: \mathbf{E}$ ratio, no effect of the $G$ antigen on the position of the $E$ band was apparent.

Gel diffusion tests on several other anti-G and anti-E sera showed that the sera $P$, no. 130 , and $P$, no. 132, were typical-although the degree of crossreactions differed somewhat. Anti-E sera showed much less cross-reaction than anti-G sera.

\section{Transformation of serotype $G$ to serotype $E$}

Under the conditions employed, transformation from serotype $\mathbf{G}$ to serotype $\mathbf{E}$ was complete, every organism of type $\mathbf{G}$ transforming to $\mathbf{E}$ with exceedingly rare exceptions. In these cases, a few organisms (less than $1.0 \%$ ) could be found which reacted neither with anti-G nor anti-E sera in immobilization tests, and were evidently of a third unidentified serotype. Furthermore, transformation was synchronous, all organisms showing uniformly decreasing ability to react with anti-G and a simultaneous uniformly increasing ability to react with anti-E serum in immobilization tests. This behaviour is reflected by changes in the immobilization titre (Fig. 3). It can be seen that the im-
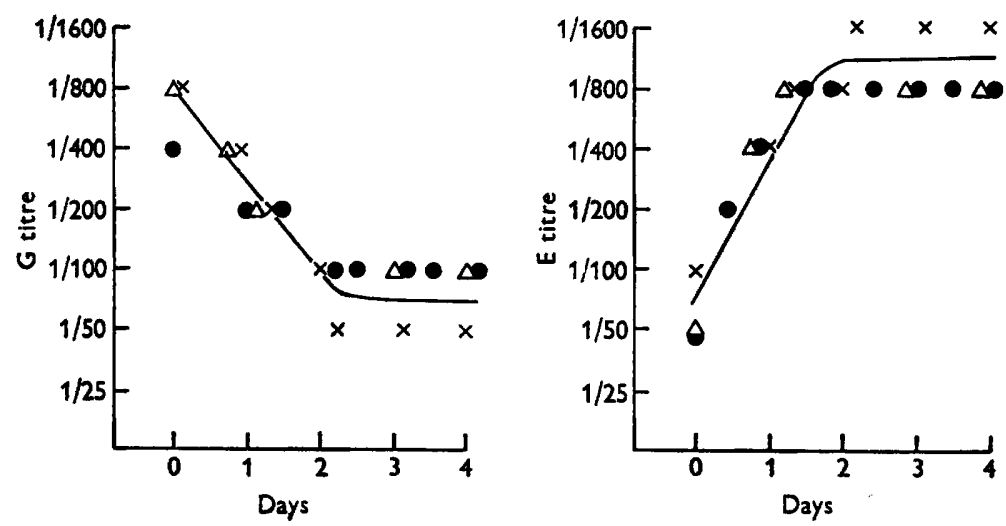

Fig. 3. Changes in immobilization titre during transformation of serotype $\mathbf{G}$ to serotype $\mathrm{E}$ in stock 28, variety 2, of Paramecium aurelia. The highest dilution of antiserum which partially immobilized organisms (gave definite avoiding reactions) is plotted against time of transformation. G organisms cross-reacted with the anti-E serum P, no. 132, and $E$ organisms cross-reacted with the anti-G serum $P$, no. 113, when the sera were used in high concentration (see Table 1). Results from three independent experiments.

mobilization titre for type $\mathrm{G}$ decreased, while the titre for type $\mathrm{E}$ showed a simultaneous increase. Thus during transformation both antigens were detectable at the same time, as other workers have reported for different transforming systems (see above). It may be noted that the maximum $\mathbf{E}$ titre was attained slightly before the $G$ titre had reached its minimum value; but the difference was small and its significance is questionable.

It was hoped that one could study quantitatively both the loss of the original antigen as well as the rise of the new one by using the gel diffusion technique. Unfortunately, it was possible to study quantitatively only the rise of the new antigen, since no sera were found which gave satisfactory resolution with 
antigen G. An attempt was made to estimate the different amounts of antigen $G$ during the initial stages of transformation (i.e. where a distinct band was obtained with antigen $G$ ) by the use of serum $P$, no. 132 (see below), but consistent results were not obtained.

When antigen extracts from transforming organisms were tested against serum $P$, no. 132, two bands were clearly present during the initial stages of transformation (see Fig. 1). These were identified as the $\mathbf{G}$ and $\mathrm{E}$ bands of pure $\mathbf{G}$ and $\mathbf{E}$ organisms by absorption and mutual dilution procedures (Preer, 1956). There was no indication of the presence of molecules of intermediate specificity, for the appearance of the tubes could be duplicated by appropriate mixtures of pure $G$ and $E$ extracts. As transformation proceeded, the $\mathbf{E}$ band moved down toward the agar-serum interface, while the $\mathrm{G}$ band tended to move up. When transformation reached the point at which $\mathrm{E}$ was in excess of $G$, only one band was observed. It was possible, however, by using serum $P$, no. 130, which had been absorbed with just enough $E$ antigen to prevent its reaction with $\mathbf{E}$, to detect the presence of antigen $\mathbf{G}$ even after $\mathrm{E}$ became the major component of the transforming system. However, reliable quantitative estimates of the $G$ antigen under these circumstances proved impossible, as noted above.
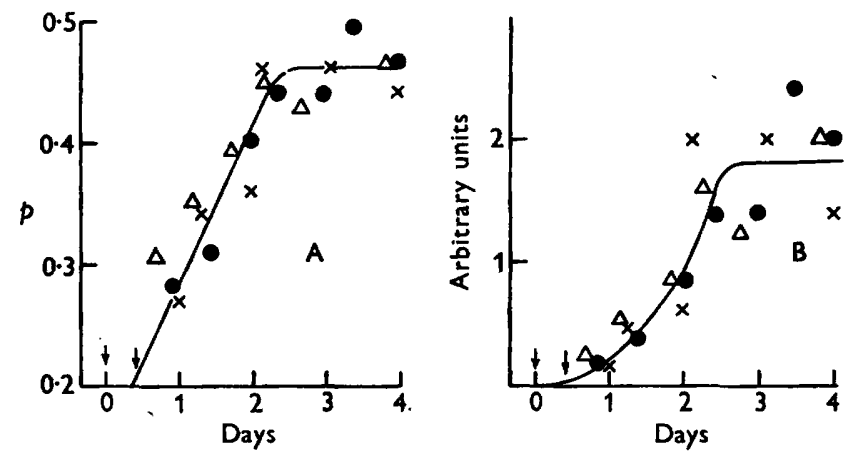

Fig. 4. Increase of antigen $\mathbf{E}$ during transformation of serotype $\mathbf{G}$ to serotype $\mathbf{E}$ in stock 28 , variety 2, of Paramecium aurelia. A shows changes in the position $(p)$ of the $\mathbf{E}$ band during transformation; $B$ shows the amount of antigen in arbitrary units computed from $p$ values in A. Each point represents an average obtained from five tubes set on the same antigen preparation. The variation between the highest and lowest value for $p$ within each set of five tubes was generally less than $0 \cdot 06$. The highest variation observed (one case) was $0 \cdot 14$. The lines have been drawn by eye. The results are from three independent experiments. The arrows pointing downward at 0 and $10 \mathrm{hr}$. indicate that the quantity of antigen was below the indicated amount.

When the band positions $p$ for antigen $\mathrm{E}$ were plotted against time of transformation, the graph obtained gave a logarithmic plot for the newly-synthesized antigen (Fig. 4 A). It should be noted, as pointed out in the Methods section, that antigen was always extracted using the same concentration of organisms $\left(1.5 \times 10^{6} / \mathrm{ml}\right.$.); hence the figures give a measure of the average amounts of antigen per Paramecium at each stage. When the amount of 
antigen was expressed in arbitrary units and these were plotted against time of transformation, a sigmoid curve was obtained (Fig. 4B).

If formation of new antigen begins at the time, or soon after the organisms are placed at $31^{\circ}$, it is clear that the curve (Fig. 4B) cannot be linear. The results could only fit a linear curve if the assumption be made that formation of new antigen does not begin until after 15-18 hr. of cultivation at $31^{\circ}$. Even so the fit would be poor, and the hypothesis of logarithmic increase provides the best agreement with the data. It may be noted that Fig. $4 \mathrm{~A}$ and the curve showing the changes in $\mathbf{E}$ titre (see Fig. 3) are practically identical.

\section{DISCUSSION}

The cross-reactions exhibited by serotypes $\mathbf{G}$ and $\mathbf{E}$ were somewhat greater than usually encountered in Paramecium, being particularly strong in the gel diffusion tests. The lack of sufficiently specific serum made it impossible to follow the original antigen quantitatively by gel diffusion as it disappeared during the transformation process; only the newly formed antigen was measured. Nevertheless, the $\mathbf{G}$ to $\mathbf{E}$ transformation was chosen for study because it is also somewhat unusual in that synchronous $100 \%$ transformation may be readily obtained in mass culture. Furthermore, the gel diffusion technique made it possible to analyse the nature of the cross-reaction between the two antigens.

Cross-reactions of the type exhibited by the $\mathbf{E}$ antiserum are well known. The serum apparently contains a minor antibody fraction capable of reacting with both the $\mathbf{G}$ and $\mathbf{E}$ antigens, and a major fraction capable of reacting only with the $\mathrm{E}$ antigen. Thus an intense band was obtained with $\mathrm{E}$ extract and a weak band displaced toward the agar-serum interface with $\mathbf{G}$ extract. Mixtures of the two antigens gave one band as long as the $\mathbf{E}$ antigen was in excess, and two bands if the $\mathrm{G}$ antigen was in excess. Similar results were obtained by Oudin (1952) on hen and duck ovalbumin, and by Preer (1956) with artificially conjugated proteins.

We have not been able to find in the literature cross-reactions identical with those exhibited by the anti-G serum. The results may be explained by assuming that the serum contains one fraction of antibody capable of precipitating both $\mathrm{G}$ and $\mathrm{E}$ antigens, and another fraction capable of precipitating $\mathrm{G}$ antigen but capable of forming only soluble complexes with the heterologous $\mathbf{E}$ antigen. Since both antigens can react with all the antibody, mixtures of the two antigens in varying proportions can give but one band when diffused against the serum. In absorption experiments either antigen in sufficient quantity may react with all the antibody. It appears, however, that in absorption tests a critical amount of heterologous $\mathrm{E}$ antigen can remove the fraction of antibody capable of precipitating $\mathbf{E}$ antigen, but still leave antibody capable of forming soluble complex with $\mathrm{E}$ and precipitating $\mathrm{G}$. When serum which has been absorbed to this degree is diffused against $\mathbf{G}$ antigen a band is formed. However, when it is set against $\mathbf{E}$ antigen, no band is formed. Mixtures of the two antigens set against the absorbed serum give a band (due 
to the $\mathbf{G}$ antigen) whose position is determined by both antigens (for both can react with the antibody). We were not able to provide decisive evidence in favour of this explanation, but Buchanan \& Oudin (1957) reported that when duck ovalbumin was diffused against heterologous anti-hen ovalbumin, soluble complexes were formed which did not precipitate but did influence the position of the zone of precipitation in gel diffusion tests.

Sonneborn (1947 and private communication) considered two possibilities to account for cross-reactions. The first is that in each serotype there is one primary antigen present in high concentration, and that antigens corresponding to other serotypes may be present in low concentration as 'secondary' antigens. These secondary antigens induce low concentrations of antibody responsible for cross-reactions, but are not involved themselves to any significant degree in the immobilization reaction. The second possibility is that each serotype has only one immobilization antigen, but that because of close immunological relationship, antibody against the antigen of one serotype may react to some extent with the antigen of other serotypes. Our data show that antibody is formed which reacts with either the $\mathbf{G}$ or $\mathbf{E}$ antigens, even when obtained against type $\mathbf{G}$ of stock 3 , which is apparently incapable of forming $\mathrm{E}$ antigen (see above). Such antibody would be expected on the basis of the second possibility. Furthermore, gel diffusion allows a direct test for secondary antigens in the extracts. The tests revealed none. Tests on mixtures of small amounts of $\mathbf{E}$ extract with $\mathbf{G}$ extract set with serum $\mathbf{P}$, no. 132, showed the test was sufficiently sensitive to detect the presence of as little as one part of $\mathrm{E}$ antigen in 127 parts of $\mathrm{G}$ antigen. The basis for the cross-reaction between $\mathrm{G}$ and $\mathrm{E}$ in stock 28 is therefore, at least in part, due to structural similarity of the antigen molecules. No evidence for the presence of secondary antigens was obtained. This is in agreement with the conclusions reached by other workers (see Beale, 1954; Finger, $1957 a$ ). Finger (1957a) suggested that the serological basis for the cross-reactions between immobilization antigens controlled by different alleles of the same genetic locus lies in similarity of structure between the antigens. The results presented here would justify extending this conclusion to apply to all cases of cross-reacting antigens in Paramecium, whether controlled by the same or different loci.

There is no critical evidence at the moment as to whether, in transformation, the old antigen contributes to the new antigen or not. Sonneborn \& Whallon (1950) reported that in transformations from type $A$ to type $B$ in stock 51, variety 4, the original A titre showed very little detectable decrease until the $B$ titre had risen to its final value. Our data indicate that the immobilization titres can be used, within limits, as a valid indication of the presence of old and new antigen. It is therefore likely that in the $\mathrm{A}$ to $\mathrm{B}$ transformation the synthesis of the new antigen is not necessarily dependent upon the loss of the old one, and hence the new antigen is not formed from the old by a change in the configuration of the molecule. It should also be pointed out that it is very difficult to conceive of the role of the genes in the determination of specificity if transformation involves a change from one specific antigen into another, rather than a de novo synthesis of new antigen, for the specific nature of each new 
serotype formed is controlled by only one specific locus, and is completely independent of genes determining the specific nature of the old serotype in which it arises. The shape of the curve for the synthesis of the new antigen makes more sense within the context of a hypothesis assuming de novo synthesis than one invoking a change in the configuration of a pre-existing molecule. Reliable data on this most important aspect of the problem, the loss of the original antigen, are unfortunately scarce. Kinetic studies of the transformation in more suitable systems using the techniques described in this paper might throw light on the matter, particularly when combined with the use of radioactive isotopes.

Gel diffusion tests on extracts of transforming paramecia demonstrated the presence of both the old and new antigens. The results of such tests could be duplicated by mixing extracts of untransformed and fully transformed organisms in varying proportions. There is no evidence for the formation of molecules of intermediate specificity. The autocatalytic kinetics of increase shown by the newly formed antigen during transformation is similar to the kinetics of adaptive enzyme formation (see Spiegelman, 1956). Indeed the capacity for induction of a new complex molecule at will in induced serotype transformation is reminiscent of the induction of adaptive enzymes. Possibly some of the techniques which have been used in studying adaptive enzyme formation might be useful in studying the mechanism of transformation in Paramecium, now that quantitative methods for measuring the antigens in vitro are available.

In a recent review Beale (1957) pointed out the difficulties standing in the way of a simple hypothesis to explain serotype determination in Paramecium aurelia. Recent evidence indicates that the serotype-correlated antigens have the properties of a protein. This, together with the similarities between antigenic transformation and adaptive enzyme formation, suggest that the explanation for serotypes and serotype determination and transformation is closely tied to the problem of protein synthesis. Various possibilities have been summarized elsewhere (Preer, 1958).

This work was aided by grants to Dr J. R. Preer from the Phi Beta Psi sorority and from the National Institutes of Health, Public Health Service.

\section{REFERENCES}

Beale, G. H. (1948). The process of transformation of antigenic type in $P$. aurelia, variety 4. Proc. nat. Acad. Sci., Wash. 34, 418.

Beale, G. H. (1952). Antigen variation in $P$. aurelia, var. 1. Genetics, 37, 62.

Beale, G. H. (1954). The Genetics of Paramecium aurelia. Cambridge University Press.

Beale, G. H. (1957). The antigen system of Paramecium aurelia. Int. Rev. Cytol. 6, 1.

Beale, G. H. \& Kacser, H. (1957). Studies on the antigens of Paramecium aurelia with the aid of fluorescent antibodies. J. gen. Microbiol. 17, 68.

Buchanan, D. J. \& Oudin, J. (1957). Cross-reactions between hen and duck egg ovalbumins. Fed. Proc. 16, 408. 
Finger, I. (1956). Immobilizing and precipitating antigens of Paramecium. Biol. Bull. Wood's Hole, 111, 358.

Finger, I. (1957a). Immunological studies of the immobilization antigens of Paramecium aurelia, variety 2. J. gen. Microbiol. 16, 350.

Finger, I. $(1957 b)$. The inheritance of the immobilization antigens of Paramecium aurelia, variety $2 . J$. Genetics, $55,361$.

Margolin, P. (1956). The ciliary antigens of stock 172, Paramecium aurelia, variety 4. J. exp. Zool. 133, 345.

OAKLey, C. L. \& Fulthorpe, A. J. (1953). Antigenic analysis by diffusion. J. Path. Bact. 65, 49.

Oudin, J. (1952). Specific precipitation in gels and its application to immunochemical analysis. Meth. Med. Res. 5, 335.

Preer, J. R. (1956). A quantitative study of a technique of double diffusion in agar. J. Immunol. 77, 52.

Preer, J. R. (1958). Nuclear and cytoplasmic differentiation in the Protozoa. In Development Cytology. Ed. D. Rudnick. New York: Ronald Press Co. (in the Press).

Preer, J. R. \& Preer, L. B. (1959). Gel diffusion studies on the antigens of isolated cellular components in Paramecium. J. Protozool. (in the Press).

Preer, J. R. \& Telfer, W. H. (1957). Some effects of non-reacting substances in the quantitative application of gel diffusion techniques. J. Immunol. 79, 288.

Sonneborn, T. M. (1947). Developmental mechanisms in Paramecium. Groreth Symp. 11, 291.

SonNeborn, T. M. (1948). Determination of heredity antigenic differences in genically identical Paramecium cells. Proc. nat. Acad. Sci., Wash. 34, 413.

Sonneborn, T. M. (1950). Methods in the general biology and genetics of Paramecium aurelia. J. exp. Zool. 113, 87.

Sonneborn, T. M. \& Whallon, J. (1950). Transformation of serotype A, stock 51, var. 4 of Paramecium aurelia. Microbiol. Genet, Bull. 3, 15.

Spiegelman, S. (1956). On the nature of the enzyme forming system. In Enzymes: Units of Biological Structure and Function, pp. 67-89. Ed. O. H. Gaebler. New York: Academic Press. 